\title{
The Prevalence of Depression among Patients with the Top Ten Most Common Cancers in South Korea
}

\author{
Boram Park, Soyoung Youn, Ki-Kyung Yi, Su-yeon Lee, Jung-Sun Lee, and Seockhoon Chung \\ Department of Psychiatry, University of Ulsan College of Medicine, Asan Medical Center, Seoul, Republic of Korea
}

\begin{abstract}
Objective Among the various psychiatric disorders, depression is a common comorbid condition in cancer patients. Due to the distinct and diverse nature of cancer, the prevalence of depression may be assumed to be affected by differences in primary cancer sites. In this study, we explored the prevalence rates of depression among the ten most prevalent cancers in South Korea using a national patient sample.

Methods This was a 1-year cross-sectional study using a national patient sample provided by the South Korean National Health Insurance in 2011. We selected all patients who had received ICD-10 codes of the 10 most prevalent cancers and major depressive disorder. Afterwards, the cancer and depression groups were merged and analyzed.

Results The MDD prevalence rate was highest in lung cancer (11.0\%), followed by non-Hodgkin's lymphoma (9.2\%), prostate (9.1\%), bladder (8.8\%), breast (7.8\%), cervix (7.8\%), colorectal (7.7\%), stomach (6.9\%), liver (6.5\%), and thyroid cancer (5.6\%). Within all cancer groups, patients with a MDD diagnosis were significantly older $(\mathrm{p}<0.05)$ than non-MDD patients. Colorectal, stomach, and thyroid cancer displayed a higher female proportion in the MDD group than the non-MDD group. In the subgroup analysis, the prevalence rate differed by age and sex.

Conclusion The prevalence of depression varied according to cancer types. Patients with lung cancer were the most prone to experience depression. Because clinical and psychological factors may influence MDD prevalence, these factors will need to be studied more closely in the future.

Psychiatry Investig 2017;14(5):618-625
\end{abstract}

Key Words Cancer, Lung cancer, Depression, Psycho-oncology, Epidemiology, South Korea.

\section{INTRODUCTION}

The number of cancer survivors has increased gradually allowing individuals to live longer after their diagnosis. ${ }^{1}$ In South Korea, over the past 13 years, overall cancer incidence rates have increased by $3.4 \%$ per year, while the mortality for cancer decreased by $2.7 \%$ per year. ${ }^{2}$ Improvement in the survival rate has increased interest in the psychological well-being of cancer patients. ${ }^{3}$ Mental health is an important issue for cancer survivors, because it affects not only their overall quality of life but also the disease progression and mortality. ${ }^{4,5}$ Among various mental illnesses, depression is a very

Received: May 6, 2016 Revised: October 17, 2016

Accepted: November 21, 2016 Available online: July 26, 2017

$\triangle$ Correspondence: Seockhoon Chung, MD, PhD

Department of Psychiatry, University of Ulsan College of Medicine, Asan Medical Center, 88 Olympic-ro 43-gil, Songpa-gu, Seoul 05505, Republic of Korea Tel: +82-2-3010-3411, Fax: +82-2-485-8381, E-mail: schung@amc.seoul.kr

(a) This is an Open Access article distributed under the terms of the Creative Commons Attribution Non-Commercial License (http://creativecommons.org/licenses/by$\mathrm{nc} / 4.0$ ) which permits unrestricted non-commercial use, distribution, and reproduction in any medium, provided the original work is properly cited. commonly observed comorbid condition. ${ }^{6.7}$ Generally, longterm survivors have a higher risk of depression, and sometimes depression results in suicide in cancer patients. ${ }^{6-9}$

Even though depression is the most investigated psychiatric disorder in cancer, it varies considerably, from about $3 \%$ to $58 \%{ }^{6,710-12}$ Such a large variability seems to be the result of several factors, such as heterogeneity of the study population, lack of standard assessment tools, different stages and treatment settings, and different cancer types. ${ }^{13,14}$ According to the distinct and diverse nature of cancer types, the prevalence of depression can be assumed to be affected by the primary cancer site. Several articles from western countries indicate that a relatively higher prevalence of depression is present in pancreatic, lung, oropharyngeal, and breast cancer patients compare with other types of cancer. ${ }^{15-18}$ However, previous study results were derived from comparing a randomly selected limited number of cancer types or by comparing several articles with different affected populations and methodological approaches.

In South Korea, sufficient reliable data to determine the prevalence of depression in cancer patients comparing differ- 
ent primary sites are lacking. The purpose of our present study was to compare the prevalence of depression in the 10 most common cancers in South Korea in 2011, ${ }^{2}$ and analyze the impact of age and sex, using a large national patient sample provided by the Korean National Health Insurance Service.

\section{METHODS}

\section{Korean Health Insurance Review and Assessment Service (HIRA)}

The HIRA-National Patient Sample (NPS) represents data collected from the National Health Insurance Service of South Korea, including information concerning patient diagnoses. ${ }^{19}$ The data set we analyzed comprised 1,375,842 patients $(3 \%$ of the total population) who received medical treatment from January 2011 to December 2011 (Serial number: HIRA-NPS2011-0101). Data was extracted with random sampling methods and stratified by age and sex. The representativeness of the sample was confirmed by previous research. ${ }^{20}$ The data included the patient's assigned identification number, age, sex, diagnosis, type of insurance, medical expenses, medications, and hospital visits (inpatient or outpatient). Diagnosis was coded according to the International Classification of Disease, Tenth Revision (ICD-10).

\section{Study subjects and data analysis}

From the total population of 1,375,832 Korean patients, patients $<18$ and $>100$ years old were excluded from the statistical analysis, resulting in 1,248,914 patients being the subjects of this study. We identified all patients who had the code "C" as a diagnosis to include cancer patients because " $\mathrm{C}$ " at the beginning of the ICD-10 code indicates malignant neoplastic disorders. Among the "C" codes, we identified the top 10 most prevalent cancer types in $\mathrm{Korea}^{2}$ : thyroid (C73), stomach (C16), colon and rectum (C18-C21), breast (C50), lung (C33 and C34), liver (C22), prostate (C61), cervix/uteri (C53), bladder (C67), and non-Hodgkin lymphoma (C82-C85). After classifying the types of cancer, we merged and matched the patient demographic data (age and sex). To identify patients with major depressive disorder (MDD), we screened those who had been diagnosed with an ICD-10 code of F32 or F33. Then, we matched the list of patients with MDD with that of patients with cancer.

Because this study considered the causal factors of each type of cancer in the development of depression, we also extracted the first date of diagnosis within a one-year duration. By comparing the first date of cancer diagnosis with the first date of psychiatric diagnosis, patients who had a psychiatric diagnosis preceding the first diagnosis of cancer were excluded. To compare cancer types, we also excluded patients with more than two cancer diagnoses. The study protocol was approved by the Institutional Review Board of the Asan Medical Center. All statistical processes were done using STATA 13.1 version 1 (Stata Corp, College Station, TX, USA).

\section{Statistical analysis}

Data were obtained on the prevalence of MDD among each cancer type, which was defined as the number of patients diagnosed with MDD among each cancer type divided by total number of each cancer patient. The p-value was calculated by the Student's t-test for continuous variables (age) and by the chi-square test for categorical variables (sex). Tests were two-tailed, and $\mathrm{p}<0.05$ was considered statistically significant. Since individual cancer types generally have their own demographic distributions and characteristics, the relative contribution of age and sex to MDD prevalence was examined by analyses of the subgroups. Subgroups were divided based on sex and age groups (group 1: 18-39 yrs, group 2: 40-59 yrs, group 3: 60-79 yrs, and group 4: 80-100 yrs). Subgroup data were analyzed using the chi-square test and Fisher's exact test. Pairwise comparisons were conducted to assess the prevalence differences among the cancer types. In the pairwise comparison, cancer in each subgroup with the highest prevalence was used as the reference. Significance levels for these comparisons were interpreted according to the Bonferroni correction. A significance level of $\mathrm{p}<0.05 / 9=0.0056$ for each of the nine comparisons was considered statistically significant. The above statistical analyses were performed with SPSS version 21.0 (IBM Corp., Armonk, NY, USA).

\section{RESULTS}

\section{Study sample characteristics}

Among the 1,248,914 patients analyzed in this study, 33,262 subjects were diagnosed with any one of the top 10 cancer types. In this sub-population, the 2,862 (8.6\%) patients with more than two cancers were excluded ( 2 sites: $n=2,585 ; 3$ sites: $\mathrm{n}=254 ; 4$ sites: $\mathrm{n}=21$; and 5 sites: $\mathrm{n}=2$ ). The remaining 30,400 patients were the total cancer subject of the prevalence rate analysis. The mean age of the enrolled population was $58.1 \pm 13.8$ yrs, and $48 \%$ of the cases were male. Thyroid cancer $(n=6,249,0.50 \%)$ was the most prevalent cancer type, followed by liver $(0.36 \%)$, colorectal $(0.34 \%)$, stomach $(0.34 \%)$, prostate $(0.26 \%)$, breast $(0.26 \%)$, lung $(0.19 \%)$, cervix $(0.09 \%)$, bladder $(0.07 \%)$, and non-Hodgkin's lymphoma $(0.04 \%)$. The patients' mean age was relatively higher for prostate $(66.3 \pm$ $11.2 \mathrm{yrs})$, lung (65.1 $\pm 13.0 \mathrm{yrs})$, and bladder cancer $(65.0 \pm 13.2$ yrs). Male predominance was seen in bladder $(73.1 \%)$, liver (66.3\%), stomach $(64.3 \%)$, and lung cancer $(62.7 \%)$. Female predominance was only seen in thyroid cancer (85.0\% female). 
General characteristics of the study sample are presented in Table 1.

\section{Prevalence of depression}

The prevalence of MDD was 3.64\% among total patients sampled. The MDD prevalence rate was highest in lung cancer (11.0\%), followed by non-Hodgkin's lymphoma (9.2\%), prostate $(9.1 \%)$, bladder $(8.8 \%)$, breast $(7.8 \%)$, cervix $(7.8 \%)$, colorectal $(7.7 \%)$, stomach (6.9\%), liver $(6.5 \%)$, and lowest in thyroid cancer (5.6\%) (Figure 1). In all cancer types, patients with a MDD diagnosis had a significantly $(\mathrm{p}<0.05)$ higher mean age than non-MDD patients (Table 2). The gender difference between the MDD and non-MDD groups is shown in Figure 2.
A statistically significant gender difference was seen in colorectal, liver, stomach, and thyroid cancer, which showed a higher female proportion in the MDD group than the non-MDD group. All of the other cancer sites had a tendency for femalepredominance that was not statistically significant.

\section{Subgroup analysis}

In the subgroup analysis, there was a general tendency that an older age and being female were associated with a higher MDD prevalence rate in each of the cancer types (Table 3). As indicated in Table 4, an overall comparison of MDD prevalence was statistically significant $(\mathrm{p}<0.05)$ in the $40-59,60-$ $79,80-100$ age subgroups of male patients and the $18-39,40-$

Table 1. Study sample characteristics

\begin{tabular}{lccccc}
\hline \multicolumn{1}{c}{ Cancer } & $\mathrm{N}$ & Prevalence $(\%)$ & Male $(\%)$ & Female $(\%)$ & Mean age \pm SD \\
\hline Thyroid & 6,249 & 0.50 & $935(15.0)$ & $5,314(85.0)$ & $50.2 \pm 12.1$ \\
Liver & 4,454 & 0.36 & $2,951(66.3)$ & $1,503(33.7)$ & $55.4 \pm 13.9$ \\
Colorectal & 4,274 & 0.34 & $2,371(55.5)$ & $1,903(44.5)$ & $62.4 \pm 12.6$ \\
Stomach & 4,222 & 0.34 & $2,714(64.3)$ & $1,508(35.7)$ & $62.1 \pm 12.3$ \\
Prostate & 3,288 & 0.26 & $3,288(100.0)$ & $0(0.0)$ & $66.3 \pm 11.2$ \\
Breast & 3,120 & 0.26 & $16(0.5)$ & $3,104(99.5)$ & $53.2 \pm 10.8$ \\
Lung & 2,332 & 0.19 & $1,463(62.7)$ & $869(37.3)$ & $65.1 \pm 13.0$ \\
Cervix & 1,107 & 0.09 & $0(0)$ & $1,107(100)$ & $53.0 \pm 13.2$ \\
Bladder & 834 & 0.07 & $583(73.1)$ & $251(26.9)$ & $65.0 \pm 13.2$ \\
NHL & 520 & 0.04 & $259(49.8)$ & $259(49.8)$ & $52.4 \pm 17.1$ \\
Total & 30,400 & 2.43 & $14,580(48.0)$ & $15,820(52.0)$ & $58.1 \pm 13.8$ \\
\hline
\end{tabular}

NHL: non-Hodgkin's lymphoma

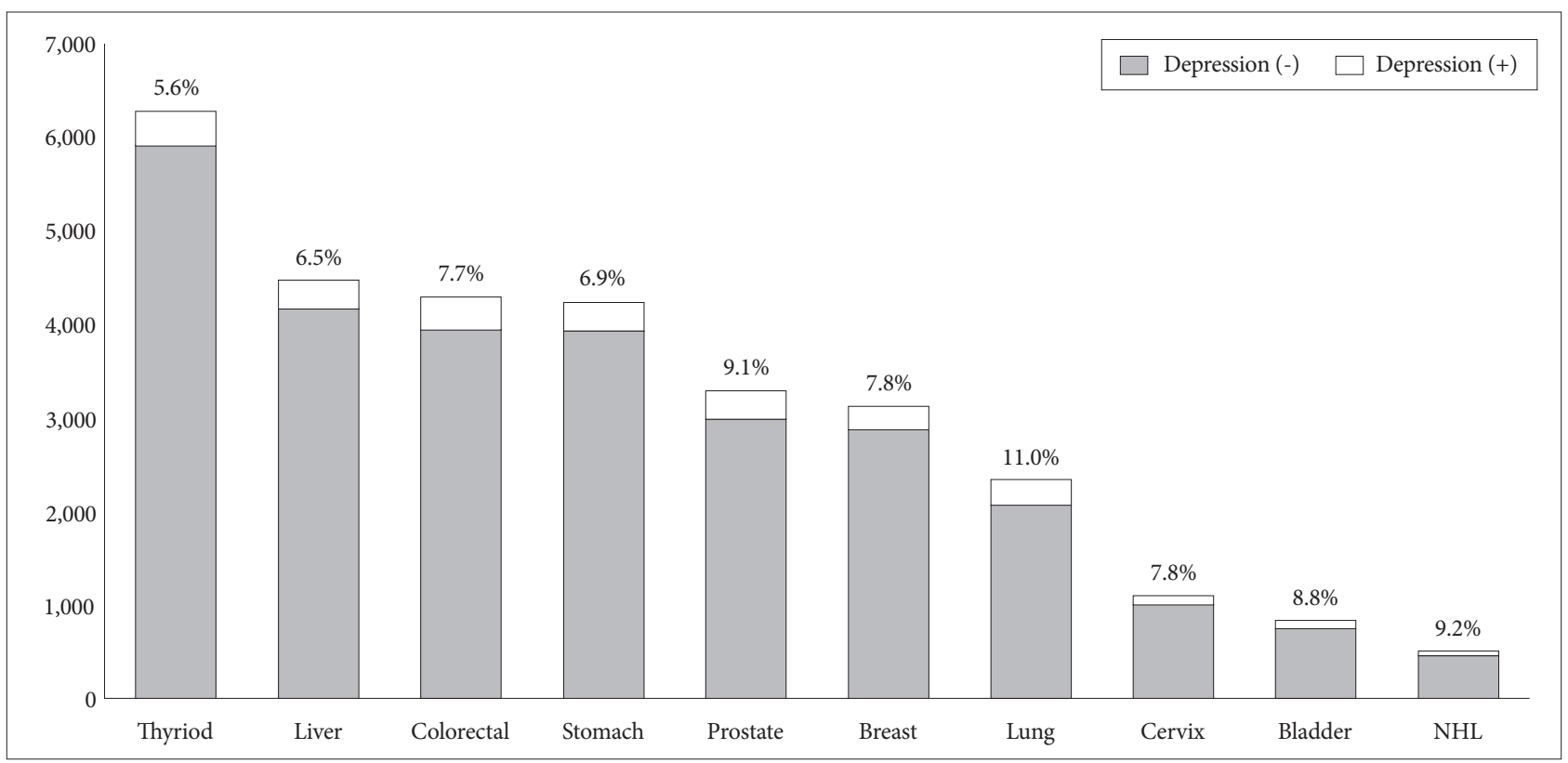

Figure 1. Prevalence of comorbid major depressive disorder in the 10 most common cancers in South Korea in 2011. NHL: non-Hodgkin's lymphoma. 
$59,80-100$ age subgroups of female patients. Depression was most prevalent in lung cancer in the 40-59 (8.0\%) and 60-79 (13.6\%) age subgroups of male patients and the $18-39$ (8.9\%) and 40-59 (11.6\%) age subgroups of female patients. In the oldest age group (80-100 yrs), thyroid (13.0\%) and NHL (27.8\%) showed the highest prevalence in males and females,

Table 2. Prevalence of MDD and the mean age difference between MDD and non-MDD groups

\begin{tabular}{|c|c|c|c|c|c|c|c|}
\hline \multirow{2}{*}{ Cancer types } & \multirow{2}{*}{$\mathrm{N}$} & \multirow{2}{*}{ Prevalence (\%) } & \multicolumn{2}{|c|}{ MDD group } & \multicolumn{2}{|c|}{ Non-MDD group } & \multirow{2}{*}{ p-value } \\
\hline & & & $\mathrm{N}$ & Mean age $\pm S D$ & $\mathrm{~N}$ & Mean age $\pm S D$ & \\
\hline Thyroid & 6,249 & 5.6 & 349 & $57.3 \pm 12.4$ & 5,900 & $49.8 \pm 12.0$ & $<0.001^{* * *}$ \\
\hline Colorectal & 4,274 & 7.7 & 330 & $66.5 \pm 11.2$ & 3,944 & $62.1 \pm 12.7$ & $<0.001^{* * *}$ \\
\hline Liver & 4,454 & 6.5 & 291 & $56.0 \pm 11.9$ & 4,163 & $55.1 \pm 13.9$ & $<0.001^{* * *}$ \\
\hline Stomach & 4,222 & 6.9 & 292 & $65.5 \pm 12.0$ & 3,930 & $61.9 \pm 12.3$ & $<0.001^{* * *}$ \\
\hline Prostate & 3,288 & 9.1 & 299 & $69.3 \pm 10.8$ & 2,989 & $66.0 \pm 11.1$ & $<0.001^{* * *}$ \\
\hline Breast & 3,120 & 7.8 & 244 & $56.2 \pm 12.1$ & 2,876 & $53.0 \pm 10.7$ & $<0.001^{* * *}$ \\
\hline Lung & 2,332 & 11.0 & 256 & $66.6 \pm 11.7$ & 2,076 & $64.9 \pm 13.2$ & $<0.05^{*}$ \\
\hline Cervix & 1,107 & 7.8 & 86 & $59.5 \pm 13.6$ & 1,021 & $52.5 \pm 13.1$ & $<0.001^{* * *}$ \\
\hline Bladder & 834 & 8.8 & 73 & $69.3 \pm 9.3$ & 761 & $64.6 \pm 13.4$ & $<0.01^{* *}$ \\
\hline NHL & 520 & 5.6 & 48 & $58.7 \pm 16.0$ & 472 & $51.7 \pm 17.1$ & $<0.01^{* *}$ \\
\hline
\end{tabular}

${ }^{*} \mathrm{p}<0.05,{ }^{* *} \mathrm{p}<0.01,{ }^{* * *} \mathrm{p}<0.001$. MDD: major depressive disorder, NHL: non-Hodgkin's lymphoma

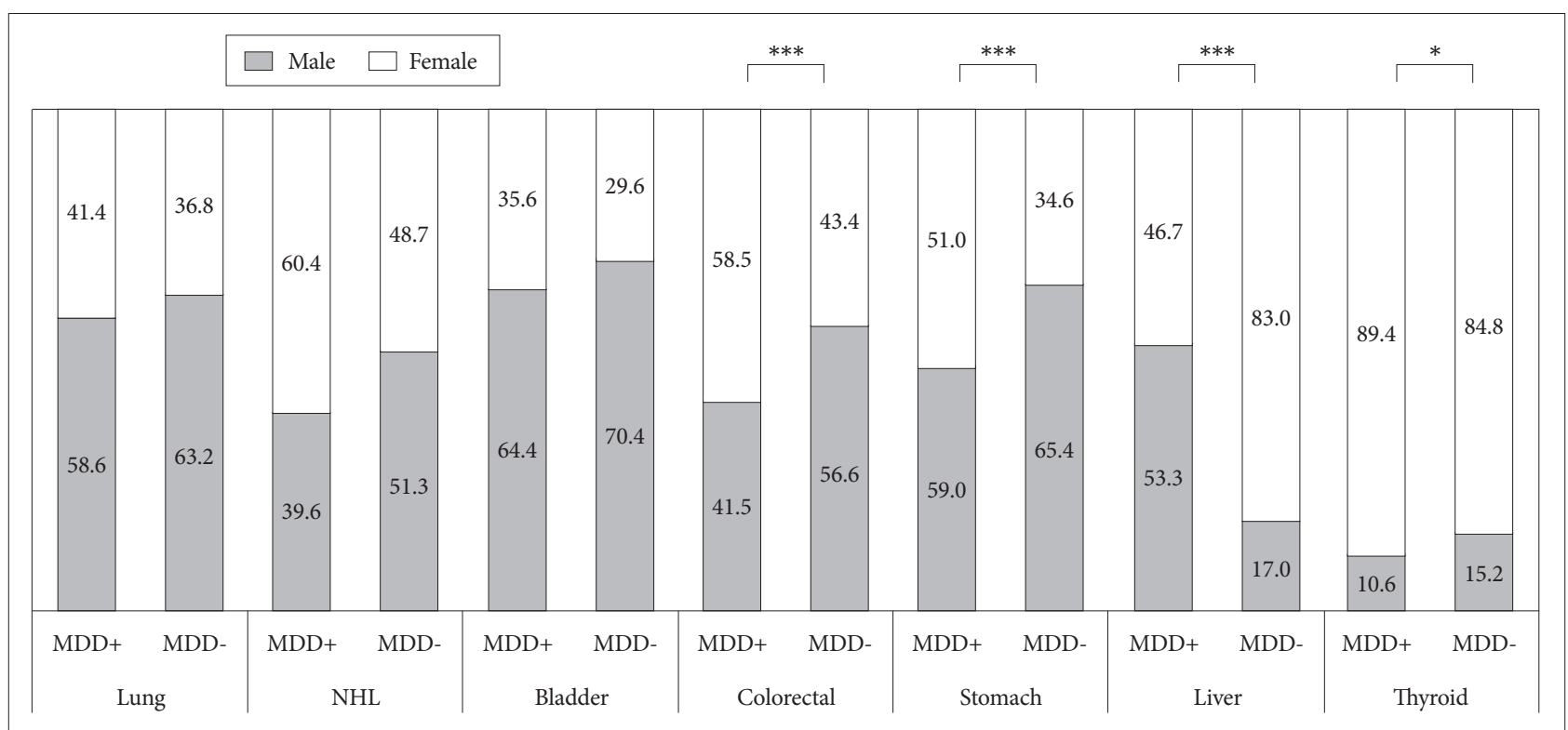

Figure 2. Gender differences between MDD and non-MDD subgroups within each cancer type. Chi-square test: ${ }^{*} p<0.05,{ }^{* *} p<0.01$, ${ }_{* * *}<0.001$, gender difference is shown as a percentage (\%). MDD: major depressive disorder, NHL: non-Hodgkin's lymphoma.

Table 3. Age and sex subgroup analysis of MDD prevalence

\begin{tabular}{cccccccccccc}
\hline Sex & $\begin{array}{c}\text { Age group } \\
\text { (yrs) }\end{array}$ & $\begin{array}{c}\text { Lung } \\
(\%)\end{array}$ & $\begin{array}{c}\text { Stomach } \\
(\%)\end{array}$ & $\begin{array}{c}\text { Colorectal } \\
(\%)\end{array}$ & $\begin{array}{c}\text { Liver } \\
(\%)\end{array}$ & $\begin{array}{c}\text { Bladder } \\
(\%)\end{array}$ & $\begin{array}{c}\text { NHL } \\
(\%)\end{array}$ & $\begin{array}{c}\text { Thyroid } \\
(\%)\end{array}$ & $\begin{array}{c}\text { Prostate } \\
(\%)\end{array}$ & $\begin{array}{c}\text { Cervix } \\
(\%)\end{array}$ & $\begin{array}{c}\text { Breast } \\
(\%)\end{array}$ \\
\hline M & $18-39$ & 4.4 & 2.1 & 3.3 & 1.2 & 0.0 & 6.1 & 1.7 & 5.7 & - & - \\
& $40-59$ & 8.0 & 3.2 & 3.9 & 5.4 & 1.4 & 7.0 & 4.5 & 6.0 & - \\
& $60-79$ & 13.6 & 5.3 & 6.4 & 7.0 & 10.6 & 6.3 & 2.2 & 7.7 & - & - \\
& $80-100$ & 9.7 & 8.8 & 7.9 & 6.3 & 10.9 & 10.6 & 13.0 & 12.3 & - & - \\
F & $18-39$ & 8.9 & 7.0 & 0.9 & 3.2 & 0.0 & 5.1 & 2.8 & - & 4.9 & 7.5 \\
& $40-59$ & 11.6 & 8.7 & 7.3 & 7.7 & 9.3 & 8.7 & 4.7 & - & 5.6 & 6.8 \\
& $60-79$ & 10.6 & 9.2 & 13.9 & 12.2 & 11.7 & 11.7 & 10.2 & - & 10.5 & 8.2 \\
& $80-100$ & 13.8 & 12.1 & 11.9 & 12.0 & 12.1 & 27.8 & 17.7 & - & 17.7 & 16.6 \\
\hline
\end{tabular}

MDD: major depressive disorder, NHL: non-Hodgkin's lymphoma, M: male, F: female 
Table 4. Pairwise comparison of each study subgroup

\begin{tabular}{|c|c|c|c|c|c|c|c|c|c|c|c|c|}
\hline \multirow{2}{*}{ Sex } & \multirow{2}{*}{$\begin{array}{c}\text { Age group } \\
\text { (yrs) }\end{array}$} & \multirow{2}{*}{$\begin{array}{c}\text { Overall } \\
\text { comparison }\end{array}$} & \multicolumn{10}{|c|}{ Pairwise comparison } \\
\hline & & & Lung & Stomach & Colorectal & Liver & Bladder & NHL & Thyroid & Prostate & Cervix & Breast \\
\hline \multirow[t]{4}{*}{ Male } & $18^{-39}$ & 0.1127 & - & - & - & - & - & - & - & - & - & - \\
\hline & $40-59$ & $<0.001^{* * *}$ & Ref & $<0.0056^{\dagger}$ & $<0.0056^{\dagger}$ & 0.0512 & 0.0051 & 0.7496 & 0.0302 & 0.1999 & - & - \\
\hline & $60-79$ & $<0.001^{* * *}$ & Ref & $<0.0056^{\dagger}$ & $<0.0056^{\dagger}$ & 0.0003 & 0.2912 & 0.1784 & $<0.0056^{\dagger}$ & $<0.0056^{\dagger}$ & - & - \\
\hline & $80-100$ & $<0.01^{* *}$ & 0.4439 & 0.3009 & 0.1989 & 0.0755 & 0.6694 & 0.7187 & Ref & 0.8879 & - & - \\
\hline \multirow[t]{4}{*}{ Female } & $18-39$ & $<0.01^{* *}$ & Ref & 0.7356 & 0.0246 & 0.1031 & 0.5676 & 0.4627 & 0.0427 & - & 0.2909 & 0.7639 \\
\hline & $40-59$ & $<0.001^{* * *}$ & Ref & 0.212 & 0.0423 & 0.0706 & 0.5879 & 0.4205 & $<0.0056^{\dagger}$ & - & $<0.0056^{\dagger}$ & 0.0072 \\
\hline & $60-79$ & 0.2155 & - & - & - & - & - & - & - & - & - & - \\
\hline & $80-100$ & $<0.05^{*}$ & 0.0253 & 0.0073 & $<0.0056^{\dagger}$ & 0.0054 & 0.0294 & Ref & 0.143 & - & 0.1851 & 0.1031 \\
\hline
\end{tabular}

$\mathrm{p}<0.05$ considered significant in overall comparisons; ${ }^{*} \mathrm{p}<0.05,{ }^{* *} \mathrm{p}<0.01,{ }^{* * *} \mathrm{p}<0.001 . \alpha<0.05 / 9=0.0056$ considered significant by Bonferroni correction in pairwise comparisons $\left({ }^{\dagger} \alpha<0.0056\right)$. NHL: non-Hodgkin's lymphoma, ref: reference

respectively. In the youngest male age group (18-39 yrs), NHL (6.1\%) showed the highest prevalence of MDD, but this group comparison was not statistically significant. Following lung cancer $(8.9 \%)$, breast $(7.5 \%)$ and stomach $(7.0 \%)$ cancer also showed a relatively high MDD prevalence in the youngest female subgroup. Alpha values for each pairwise comparison are listed in Table 4.

\section{DISCUSSION}

Our current analysis indicated that among the 10 most common cancer types in South Korea, depression is most prevalent in lung cancer patients (11.0\%). Cancer patients with depression showed a higher mean age and tendency toward a female predominance. In the subgroup analysis, the prevalence of depression differed by both age and sex. The oldest group (80-100 yrs) of both sexes, in particular, showed different patterns of depression prevalence from the other age groups. Thyroid cancer showed the highest prevalence rate (13.0\%) in males, and NHL had the highest prevalence (27.8\%) in females.

We used national insurance data to compare the overall prevalence of depression in several cancer types and we also sought to assess psychiatric diagnosis and management in clinical practice. The one-year prevalence rate of depression was highest in lung cancer cases. In subgroup analysis, depression was highest in lung cancer patients aged $40-59$ yrs in both sexes. Other large population studies have also shown a higher prevalence of depression in lung cancer than in other cancer types. In a previous cross-sectional study from Scotland, the depression rate from lung cancer was $13.1 \%$ using a routine depression screening tool in the clinics. ${ }^{21}$ A previous Korean study using national registry data also found that the highest incidence rate of psychiatric disorders, including depression, was in lung cancer patients. ${ }^{22} \mathrm{~A}$ relatively higher level of psychological distress in lung cancer patients than in other types of cancer patients has also been reported. ${ }^{23-25}$ In addition, the poor prognosis of this disease and greater patient burden during treatment causes high distress. Current therapies are still ineffective, and multi-modality treatment approaches are inevitable. ${ }^{18}$ Several factors, including high mortality, appear to contribute to high psychological distress in lung cancer. In 2011 in Korea, the year of our current study dataset, the most common primary site for cancer deaths was in the lung. ${ }^{2}$

NHL also showed a high prevalence for depression in our analysis. In a study by Zabora et al., ${ }^{18} \mathrm{NHL}$ was found to be the fifth most distressful diagnosis (53.4\% rate of depression) among 14 cancer types. However, depression in hematological cancer had not received much analysis in the adult population. Since some patients with NHL can expect to be cured, we hypothesized that the prevalence might be lower than other oncological cancers with a poorer prognosis, but we found NHL to have a relatively high prevalence of depression in our present investigation. We hypothesize that this unexpected result might be due to a spike in the level of psychiatric distress during aggressive chemotherapy, but further study is needed to assess this possibility.

Gender-specific cancers such as breast, cervical, and prostate cancers also showed a relatively high prevalence of depression in our current series. This pattern was consistent with that reported by other studies. In a report by Jane et al., among five selected cancer types, the depression prevalence was found to be highest in lung cancer (13.1\%), followed by gynecological (10.9\%) and breast cancer (9.3\%). ${ }^{21}$ In another Korean population-based study, breast cancer patients also showed a high incidence (70.30/1,000 person-years) of psychiatric disorders among five major cancer types, following lung cancer (75.37/1,000 person-years). ${ }^{22}$ In our current subgroup analysis, the rate of depression was the $2 \mathrm{nd}$ or $3 \mathrm{rd}$ most common in prostate cancer, ranging from $5.7 \%$ to $12.3 \%$, across all age groups. In young breast cancer patients (18-40 yrs), the prev- 
alence of depression was relatively higher (7.5\%) compared to other cancers. This finding is consistent with an earlier study describing the higher risk of depression in younger breast cancer survivors. ${ }^{26} \mathrm{~A}$ Korean epidemiological study of breast cancer has also reported that depressive disorder was diagnosed in $4.94 \%$ of women with breast cancer, which was higher than the general population. In our current age-specific incidence rate analysis, the rate was highest in the oldest aged group ( $\geq 80 \mathrm{yrs}$ ) as seen in our subgroup analysis. ${ }^{27}$

In the cervical cancer cases in our current series, the prevalence of depression was most prominent in the oldest age group. A previous Korean study of cervical cancer survivors has indicated that they had clinically significant greater problems with social functioning, body image, and sexual functioning. ${ }^{28}$

The incidence of thyroid cancer has been increasing over the last few decades and this has become the most common cancer in Korea. Decreased risk factor exposure and increased detection has resulted in steady declines in mortality.2, Despite its increasing prevalence, thyroid cancer showed the lowest prevalence of depression in our current study. Thyroid cancer is now perceived by patients as a remarkably treatable and curable disease. We assume that patients may have lower distress levels than those with other cancers with worse prognoses. This speculation is supported by a previous cross-sectional study in 13 thyroid cancer patients with hypothyroidism. Unexpectedly in that study, the severity of depressive symptoms was in the normal range, and depression prevalence was also comparable to the reference populations. ${ }^{30}$

As in the general population, females showed a higher prevalence of depression than the male group of same age in our current analysis. Colorectal, stomach, liver and thyroid cancer showed statistical significance for female predominance. Female predominance in depression is consistent with several other studies with a heterogeneous group of different cancer types and stages. ${ }^{17,31} \mathrm{~A}$ recent Korean population-based study also revealed that being female was a risk factor for a psychiatric comorbidity. ${ }^{22}$ However, there were several inconsistent findings in that study of no difference in depression rates by sex. Two other studies considered cancer stage and prognosis, which were not available from our current data, and found that the gender disparity was prominent in groups with a better prognosis but not in those with a poorer prognosis. ${ }^{32-34}$

We found that the depression group in all cancer types had a significantly older mean age. Also, in the subgroup analysis, we found a tendency for the oldest aged group to show higher MDD prevalence rates. A recent Korean study also indicated that older age is a risk factor for psychiatric in cancer patients. ${ }^{22}$ According to another study in cancer patients, older cancer patients have a tendency to use an avoidance coping strategy and this habit is associated with a higher risk of depression. ${ }^{35}$ However, there have been several studies regarding the higher depression rate in younger cancer patients that suggest better resilience in older cancer patients. ${ }^{36-38}$ We speculate that there may be a different pattern of mental health service utilization such that older patients are more likely to seek medical help and are less fearful about psychiatric diagnosis and treatment. In addition, since our current data do not address disease duration, it is possible that individual variations in this may contribute to high prevalence because older patients have a greater chance of having an advanced stage tumor, experience of recurrence, high vulnerability to physical symptoms, and longer duration of treatment.

A number of existing psychiatric studies in cancer patients are limited by a focus on a specific cancer type, small sample sizes, different measurement tools and diagnostic criteria, and various disease stage and trajectories. In this context, our study had several strengths such as the large, randomly selected sample population used to minimize selection bias and the ability to study several cancer types with the same approach. Second, using insurance data, we compared prevalence rates derived from real-world psychiatric diagnostic information. Compared to other small sample-sized studies, the overall prevalence rate of depression in our analysis tended to be relatively low, ranging from $5 \%$ to $15 \%$. This difference may derive from an under-diagnosis and under-treatment in clinical practice. Based on our clinical experience and other study results, cancer patients are reluctant to be labeled with a psychiatric diagnosis. ${ }^{39,40}$ We speculate that the actual prevalence might be higher than our results suggest. Third, there was an advantage of our data related to the current insurance laws in Korea. The Korean health system is underpinned by a National Health Insurance (NHI) framework that covers the entire population, with graded contributions according to economic status. Current insurance coverage for antidepressants for more than 60 days is only provided when the medication is prescribed by a psychiatrist. Thus, the majority of current depression diagnoses and antidepressant prescriptions in our dataset were confined to psychiatric departments rather than other medical departments. This increases the chance of diagnostic accuracy.

It must be noted however that the results of our present study need to be considered in the context of several limitations. First, this was an epidemiological study, and accessible variables were limited. There were also unmeasured confounding factors we could not consider. Cancer trajectory, illness duration, current stage, and previous history of a psychiatric disorder are examples of these. Second, the causal relationship between cancer and a psychiatric condition was uncertain because of our cross-sectional study design. However, to add 
credence to the possibility of a causal relationship, we excluded patients who had a depression diagnosis before the cancer diagnosis during the 1-year study period. Although we tried to manage this problem, we could not completely overcome this limitation. Some people became depressed during their work-up period before the final diagnosis, and our exclusion criterion could have been an over-exclusion. Third, the reliability and validity of the diagnoses in our series were not as qualified as structured interviews by trained experts. There are differences between the diagnostic methods of each physician. Fourth, we only included patients with MDDs, which may have led to an underestimation of the true extent of depression in cancer patients. We did not include adjustment disorder (F40-48) because of its relatively vague and encompassing characteristic. Sometimes this disorder can be confused with temporary depressed mood or anxiety accompanied with a cancer diagnosis that can be viewed as a normal response. However, adjustment disorder is also used as a less stigmatizing label for depression treatment and may also represent an early diagnosis of major depression. Finally, the poisson regression analysis might be appropriate to estimate prevalence ratio in this study. However, it was not easy to get the age-standardized prevalence of each 10 most common cancer. This methodological consideration is one of limitations of this study.

In conclusion, using National Health Insurance claims data from Korea, we found that the depression prevalence rate in cancer patients is approximately from $5 \%$ to $15 \%$, which is higher than the general population in the same sample (3.64\%). In addition, the prevalence of depression was highest in lung cancer patients among the most common top 10 cancers in Korea but the order of this prevalence rate changed according to sex and age. These findings provide important information for clinical considerations to detect and treat depression in patients with different cancers. Particular attention should be given to elderly, female, and to lung cancer patients with psychological distress. Further studies of each cancer type are needed to expand our understanding of the different risk factors for depression.

\section{REFERENCES}

1. Welch HG, Schwartz LM, Woloshin S. Are increasing 5-year survival rates evidence of success against cancer? JAMA 2000;283:2975-2978.

2. Jung KW, Won YJ, Kong HJ, Oh CM, Lee DH, Lee JS. Cancer statistics in Korea: incidence, mortality, survival, and prevalence in 2011. Cancer Res Treat 2014;46:109-123.

3. Young T, Maher J. Collecting quality of life data in EORTC clinical trials--what happens in practice? Psychooncology 1999;8:260-263.

4. Satin JR, Linden W, Phillips MJ. Depression as a predictor of disease progression and mortality in cancer patients: a meta-analysis. Cancer 2009;115:5349-5361.

5. Wedding U, Koch A, Rohrig B, Pientka L, Sauer H, Hoffken K, et al.
Depression and functional impairment independently contribute to decreased quality of life in cancer patients prior to chemotherapy. Acta Oncol 2008;47:56-62.

6. Henriksson MM, Isometsa ET, Hietanen PS, Aro HM, Lonnqvist JK. Mental disorders in cancer suicides. J Affect Disord 1995;36:11-20.

7. Lloyd-Williams M, Friedman T. Depression in palliative care patients-a prospective study. Eur J Cancer Care (Engl) 2001;10:270-274.

8. Dalton SO, Laursen TM, Ross L, Mortensen PB, Johansen C. Risk for hospitalization with depression after a cancer diagnosis: a nationwide, population-based study of cancer patients in Denmark from 1973 to 2003. J Clin Oncol 2009;27:1440-1445.

9. Brinkman TM, Zhang N, Recklitis CJ, Kimberg C, Zeltzer LK, Muriel $\mathrm{AC}$, et al. Suicide ideation and associated mortality in adult survivors of childhood cancer. Cancer 2014;120:271-277.

10. Warmenhoven F, van Rijswijk E, van Weel C, Prins J, Vissers K. Low prevalence of depressive disorder in ambulatory advanced cancer patients using the Schedules for Clinical Assessment in Neuropsychiatry (SCAN 2.1). J Affect Disord 2012;136:1209-1211.

11. Meyer HA, Sinnott C, Seed PT. Depressive symptoms in advanced cancer. Part 2. Depression over time; the role of the palliative care professional. Palliat Med 2003;17:604-607.

12. Bodurka-Bevers D, Basen-Engquist K, Carmack CL, Fitzgerald MA, Wolf JK, de Moor C, et al. Depression, anxiety, and quality of life in patients with epithelial ovarian cancer. Gynecol Oncol 2000;78:302-308.

13. Lynch TR, Mendelson T, Robins CJ, Krishnan KR, George LK, Johnson CS, et al. Perceived social support among depressed elderly, middleaged, and young-adult samples: cross-sectional and longitudinal analyses. J Affect Disord 1999;55:159-170.

14. Ciaramella A, Poli P. Assessment of depression among cancer patients: the role of pain, cancer type and treatment. Psychooncology 2001;10: 156-165.

15. Massie MJ. Prevalence of depression in patients with cancer. J Natl Cancer Inst Monogr 2004:57-71.

16. Angelino AF, Treisman GJ. Major depression and demoralization in cancer patients: diagnostic and treatment considerations. Support Care Cancer 2001;9:344-349.

17. Carlson LE, Angen M, Cullum J, Goodey E, Koopmans J, Lamont L, et al. High levels of untreated distress and fatigue in cancer patients. Br J Cancer 2004;90:2297-2304.

18. Zabora J, BrintzenhofeSzoc K, Curbow B, Hooker C, Piantadosi S. The prevalence of psychological distress by cancer site. Psychooncology 2001;10:19-28.

19. Park YT, Yoon JS, Speedie SM, Yoon H, Lee J. Health insurance claim review using information technologies. Healthc Inform Res 2012;18: 215-224.

20. Kim LY, Sakong J, Kim Y, Kim SR, Kim SY, Tchoe BH, et al. Developing the inpatient sample for the National Health Insurance claims data. Health Policy Manag 2013;23:152-161.

21. Walker J, Hansen CH, Martin P, Symeonides S, Ramessur R, Murray G, et al. Prevalence, associations, and adequacy of treatment of major depression in patients with cancer: a cross-sectional analysis of routinely collected clinical data. Lancet Psychiatry 2014;1:343-350.

22. Lee BO, Choi WJ, Sung NY, Lee SK, Lee CG, Kang JI. Incidence and risk factors for psychiatric comorbidity among people newly diagnosed with cancer based on Korean national registry data. Psychooncology 2015;24:1808-1814.

23. Chambers SK, Baade P, Youl P, Aitken J, Occhipinti S, Vinod S, et al. Psychological distress and quality of life in lung cancer: the role of health-related stigma, illness appraisals and social constraints. Psychooncology 2015;24:1569-1577.

24. Chapple A, Ziebland S, McPherson A. Stigma, shame, and blame experienced by patients with lung cancer: qualitative study. BMJ 2004; 328:1470.

25. Marlow LA, Waller J, Wardle J. Does lung cancer attract greater stigma than other cancer types? Lung Cancer 2015;88:104-107. 
26. Avis NE, Levine B, Naughton MJ, Case LD, Naftalis E, Van Zee KJ. Agerelated longitudinal changes in depressive symptoms following breast cancer diagnosis and treatment. Breast Cancer Res Treat 2013;139:199206.

27. Kang JI, Sung NY, Park SJ, Lee CG, Lee BO. The epidemiology of psychiatric disorders among women with breast cancer in South Korea: analysis of national registry data. Psychooncology 2014;23:35-39.

28. Park SY, Bae DS, Nam JH, Park CT, Cho CH, Lee JM, et al. Quality of life and sexual problems in disease-free survivors of cervical cancer compared with the general population. Cancer 2007;110:2716-2725.

29. La Vecchia C, Malvezzi M, Bosetti C, Garavello W, Bertuccio P, Levi F, et al. Thyroid cancer mortality and incidence: a global overview. Int J Cancer 2015;136:2187-2195.

30. Tagay S, Herpertz S, Langkafel M, Erim Y, Bockisch A, Senf W, et al. Health-related Quality of Life, depression and anxiety in thyroid cancer patients. Qual Life Res 2006;15:695-703.

31. Strong V, Waters R, Hibberd C, Rush R, Cargill A, Storey D, et al. Emotional distress in cancer patients: the Edinburgh Cancer Centre symptom study. Br J Cancer 2007;96:868-874.

32. Wilson KG, Chochinov HM, Skirko MG, Allard P, Chary S, Gagnon PR, et al. Depression and anxiety disorders in palliative cancer care. J Pain Symptom Manage 2007;33:118-129.

33. Hopwood P, Stephens RJ. Depression in patients with lung cancer: prevalence and risk factors derived from quality-of-life data. J Clin Oncol 2000;18:893-903.
34. Miller S, Lo C, Gagliese L, Hales S, Rydall A, Zimmermann C, et al. Patterns of depression in cancer patients: an indirect test of genderspecific vulnerabilities to depression. Soc Psychiatry Psychiatr Epidemiol 2011;46:767-774

35. Aarts JW, Deckx L, van Abbema DL, Tjan-Heijnen VC, van den Akker M, Buntinx F. The relation between depression, coping and health locus of control: differences between older and younger patients, with and without cancer. Psychooncology 2015;24:950-957.

36. Brintzenhofe-Szoc KM, Levin TT, Li Y, Kissane DW, Zabora JR. Mixed anxiety/depression symptoms in a large cancer cohort: prevalence by cancer type. Psychosomatics 2009;50:383-391.

37. Linden W, Vodermaier A, Mackenzie R, Greig D. Anxiety and depression after cancer diagnosis: prevalence rates by cancer type, gender, and age. J Affect Disord 2012;141:343-351.

38. Zlatar ZZ, Meier EA, Montross Thomas LP, Palmer BW, Glorioso D, Marquine MJ, et al. Life satisfaction and its correlates among older cancer survivors: critical role of psychosocial factors. Psychooncology 2015;24:241-244.

39. Carlson LE, Waller A, Mitchell AJ. Screening for distress and unmet needs in patients with cancer: review and recommendations. J Clin Oncol 2012;30:1160-1177.

40. Mitchell AJ, Vahabzadeh A, Magruder K. Screening for distress and depression in cancer settings: 10 lessons from 40 years of primary-care research. Psychooncology 2011;20:572-584. 